\title{
MARGUERAT (Daniel), REYMOND (Bernard), Le Protestantisme et son avenir
}

Genève, Labor et fides, 1998, 150 p.

\section{Solange Wydmusch}

\section{OpenEdition}

\section{Journals}

Édition électronique

URL : http://journals.openedition.org/assr/20680

DOI : $10.4000 /$ assr.20680

ISSN : $1777-5825$

\section{Éditeur}

Éditions de l'EHESS

Édition imprimée

Date de publication : 1 juillet 2000

Pagination : 127-128

ISBN : 2-222-96691-4

ISSN : 0335-5985

\section{Référence électronique}

Solange Wydmusch, " MARGUERAT (Daniel), REYMOND (Bernard), Le Protestantisme et son avenir 》, Archives de sciences sociales des religions [En ligne], 110 | avril-juin 2000, document 110-82, mis en ligne le 19 août 2009, consulté le 21 septembre 2020. URL : http://journals.openedition.org/assr/ 20680 ; DOI : https://doi.org/10.4000/assr.20680

Ce document a été généré automatiquement le 21 septembre 2020

(C) Archives de sciences sociales des religions 


\section{MARGUERAT (Daniel), REYMOND (Bernard), Le Protestantisme et son} avenir

Genève, Labor et fides, 1998, 150 p.

\section{Solange Wydmusch}

\section{RÉFÉRENCE}

MARGUERAT (Daniel), REYMOND (Bernard), Le Protestantisme et son avenir, Genève, Labor et fides, 1998, $150 \mathrm{p}$.

1 Le présent ouvrage rassemble les textes des conférences données à l'Université de Lausanne sur le thème général du protestantisme et de son avenir au travers de la question de l'identité protestante aujourd'hui. Partant du constat de la nécessaire transformation et évolution dans les Églises de la Réforme, les auteurs cherchent à analyser l'identité protestante sur fond de modernité, voire de post-modernité. Il apparaît dans plusieurs contributions (J-P. Willaime, André Gounelle, Klauspeter Blaser), que le protestantisme se caractérise à présent par sa mouvance. Il doit se situer par rapport à une pluralisation des options éthiques et semble souvent pris de cours. Par ailleurs, la présence au sein même du protestantisme d'une multitude de mouvements et groupes pose la question de son existence. Dans sa contribution sur les "Risques et atouts de la précarité protestante", Jean-Paul Willaime après avoir présenté la précarisation du christianisme en Europe occidentale précise sa thèse sur la précarité protestante. Cette dernière n'engendre nullement le « retour triomphal du catholicisme ", elle manifeste simplement la fragilité sociologique du protestantisme. Il distingue six raisons : il privilégie le discours au rite, l'individu à l'institution, il ébranle l'autorité des professionnels du religieux, il génère un provincialisme religieux, il est pris dans une tension entre libéralisme et fondamentalisme, enfin, par son ouverture à l'œcuménisme, il ne transmet pas véritablement d'identité religieuse. La contribution 
de Klauspeter Blaser sur "l'éclatement du protestantisme " s'interroge sur l'efficacité du message de réconciliation au sein même de la confession. Fait remarquable, l'Église n'est que peu évoquée dans l'ouvrage, c'est peut-être là une marque du protestantisme, la culture est survalorisée. 